\title{
A Study on Identification of Development Status of MASS Technologies and Directions of Improvement
}

\author{
Chong-Ju Chae ${ }^{1}$, Mingyu Kim ${ }^{2} * *(\mathbb{D})$ and Hyung-Ju Kim ${ }^{3}$ \\ 1 Korea Institute of Maritime and Fisheries Technology (KIMFT), 367 Haeyang-ro, Busan 49111, Korea; \\ katheshe76@seaman.or.kr \\ 2 Korea Center for International Maritime Safety Cooperation (KMC), 492 Hannuri-daero, Sejong 30103, Korea \\ 3 Department of Maritime Operations, University of South-Eastern Norway (USN), 215 Raveien, 3184 Vestfold, \\ Norway; Hyungju.kim@usn.no \\ * Correspondence: mingyu.kim@imkmc.or.kr; Tel.: +82-(0)70-4923-4536
}

Received: 28 May 2020; Accepted: 29 June 2020; Published: 30 June 2020

check for updates

\begin{abstract}
The introduction of the maritime autonomous surface ship (MASS) to the maritime industry will open up a new era and bring about a new paradigm shift in terms of cost efficiency, maritime accidents, and human resources. Various studies are currently being conducted to realize the MASS. Understanding the scope and direction of these studies will be of great help for future MASS research. In this study, the current development status of technologies for autonomous ships is identified, and considerations and directions of improvement are suggested for six major research fields that cover all technological issues of MASS. Firstly, the results of the regulatory scoping exercise (RSE) on the International Maritime Organization (IMO) conventions to accept MASSs are identified; in particular, human elements are identified as vital issues to be considered for the design and operation of MASSs. Secondly, various studies on the decision-making system are identified, and the future direction is suggested. Thirdly, in terms of ship design and propulsion system, design changes for autonomous cargo ships are investigated, with their potential impacts to be considered. Fourthly, the communication system will need to be robust and supported by multiple systems to minimize potential risk with third-party infrastructures, and suitable protection of systems, networks, and data will be required as an integral part of the safety system for cybersecurity. Fifthly, issues of maintenance and repair are identified, with a maintenance strategy to be considered. Lastly, hazard analysis of the autonomous ship is explored, and system-theoretic process analysis (STPA) and the functional resonance analysis method (FRAM) are identified as the most representative new methods that can be used for hazard analysis of autonomous ships.
\end{abstract}

Keywords: maritime autonomous surface ships (MASSs); autonomous vessels; shore control center (SCC); regulatory scoping exercise (RSE); human elements; risk assessment; HAZID

\section{Introduction}

At the 8th session of the Maritime Safety Committee (MSC) in March 1964, the IMO first discussed automation in ships [1]. Since then, development and research on the automation of ships have been ongoing, and now the maritime industry is preparing for the operation of MASSs based on technology development. Several MASS research projects have been developed, conducted and are ongoing globally: Maritime Unmanned Navigation through Intelligence in Networks [2]; DNV-GL Revolt [3]; Kongsberg maritime autonomous shipping [4]; NYK Maritime Autonomous Surface Ships Trial [5]; Korea Autonomous ship project [6]; Yara Birkeland [7]. The first autonomous cargo ship will be in operation soon after 2020. 
Various research projects and studies on MASSs are facing challenges because of the complicated operation concept and new technologies. To identify and address these issues, IMO has conducted MASS regulatory scoping exercise (RSE) in order to accommodate technological development for MASS [8] and considered human factors, especially for an autonomous ship without crew [9]. There has been much research to analyze problems and challenges and to suggest possible solutions: problem identification in the remote control center for MASS operation [10]; design-based solutions and operation-based solutions in order to resolve the human factor challenges [11]; MASS application of current STCW 1978 convention requirements [12]; deep learning as a decision support system for MASS operation [13]; an artificial neural network decision-making system to help optimize the use of fuel for ships [14]; STPA for the risk assessment of autonomous ships [15]. Currently, these studies are being conducted in a wide variety of fields. Therefore, it can be very helpful for researchers who are performing related research to check how far research has gone on various fields of MASSs that are currently underway and to suggest future research directions based on this.

In this study, necessary technologies and considerations are identified through a literature review for practical operation of the MASS, and the future direction of the research should be based on the identification of the current challenges facing the safe operation of MASSs. To this end, this study basically considers eight techniques, which were identified in a previous study [16] for MASS operation, that are different from conventional vessels. The results of the IMO MASS RSE were analyzed in order to identify further issues, taking into account the importance of the application of the IMO international convention. In addition, this study analyzes decision support systems, designs of MASSs, the communication system and cybersecurity of MASSs, maintenance and repair, hazard analyses for MASSs that were identified through previous studies, and IMO MASS RSE. Through this, this study will cover all issues regarding MASS operation and suggest the direction of research.

\section{IMO MASS RSE and Human Element Issues}

Technological development is a key element to the realization of MASSs, but prior to this, it must meet the requirements of international instruments in order to enable the international navigation of the MASS. Basically, autonomous vessels have the initial expectation, where they have to be at least as safe as the most advanced manned ships [17]. To confirm this, MSC 98 decided to start the MASS RSE [18], and the two-year work will be completed by the MSC 102nd session in 2020 [19].

The objective of the IMO RSE for MASS is to assess the degree of autonomy that may affect existing regulatory frameworks in order to address MASS operations. To facilitate the process of the RSE, the degrees of autonomy were categorized into four phases at MSC 99, as shown in Figure 1 [8]. It should be noted that MASS can operate in more than one degree of autonomy during a single voyage.

\begin{tabular}{|c|c|c|c|}
\hline MASS Degree 1 & MASS Degree 2 & MASS Degree 3 & MASS Degree 4 \\
\hline $\begin{array}{l}\text { Ship with } \\
\text { automated process } \\
\text { and decision } \\
\text { support }\end{array}$ & $\begin{array}{l}\text { Remotely controlled } \\
\text { ship with seafarers } \\
\text { on board }\end{array}$ & $\begin{array}{l}\text { Remotely controlled } \\
\text { ship without } \\
\text { seafarers on board }\end{array}$ & $\begin{array}{l}\text { Fully autonomous } \\
\text { ship }\end{array}$ \\
\hline $\begin{array}{l}\text { - Seafarers on board } \\
\text { Some operations } \\
\text { automated and at } \\
\text { times unsupervised } \\
\text { with seafarers } \\
\text { ready to control }\end{array}$ & $\begin{array}{l}\text { Controlled and } \\
\text { operated from } \\
\text { another location } \\
\text { - Seafarers available } \\
\text { on board to take } \\
\text { control and } \\
\text { operate }\end{array}$ & $\begin{array}{l}\text { - Controlled and } \\
\text { operated from } \\
\text { another location } \\
\text { - No seafarers on } \\
\text { board }\end{array}$ & $\begin{array}{l}\text { The operating } \\
\text { system of MASS is } \\
\text { able to make } \\
\text { decisions and } \\
\text { determine actions } \\
\text { by itself }\end{array}$ \\
\hline
\end{tabular}

Figure 1. Degrees of autonomy. 
The MASS RSE was divided into two steps, and the first step was completed at the MSC 101 meeting in 2019. In the first step of RSE, the contents of 14 international instruments under MSC were analyzed and identified as the following four categories, which had been decided during the MSC 99th session.

A. Apply to MASS and preclude MASS operations; or

B. Apply to MASS and do not preclude MASS operations and require no actions; or

C. Apply to MASS and do not preclude MASS operations but may need to be amended or clarified, and/or may contain gaps; or

D. Have no application to MASS operations.

In the second step, an analysis has been conducted to determine the most appropriate way of addressing MASS operations, taking into account the human element and technology and operational factors. The second step of MASS RSE will be completed by the 102nd MSC session in 2020. In the second step, the contents of the 14 international instruments under MSC were analyzed and identified as the following four categories.

I. Equivalences as provided for by the instruments or developing interpretations; and/or

II. Amending existing instruments; and/or

III. Developing new instruments; or

IV. None of the above, as a result of the analysis.

As there are limitations in handling the results of all contents of MSC-related instruments, the results of the MASS RSE for the Standards of Training, Certification and Watchkeeping Convention (STCW 1978, as amended) - as one of the key instruments of IMO in regulating the minimum qualification for seafarers-are as follows [9]. The most important aspect of the MASS RSE of the STCW 1978 Convention is its application [12]. According to article 3 (Application) of the STCW Convention, it is stipulated that the convention only applies to ships with seafarers on board [20]. Based on this understanding, the results of MASS RSE, depending on autonomy degrees for the STCW convention, are as listed in Table 1.

Table 1. Results of the maritime autonomous surface ship (MASS) regulatory scoping exercise (RSE) Step 2 for Standards of Training, Certification, and Watchkeeping Convention (STCW 1978), as amended.

\begin{tabular}{|c|c|c|}
\hline Degree of Autonomy & $\begin{array}{c}\text { The most appropriate way(s) of addressing MASS } \\
\text { operations (I, II, III, IV) }\end{array}$ & $\begin{array}{l}\text { Reasons for selecting the most appropriate way(s) } \\
\text { of addressing MASS operations }\end{array}$ \\
\hline Degree 1 & Categories I and/or II & $\begin{array}{l}\text { With seafarers serving onboard, the Convention } \\
\text { and Code in its entirety remain applicable to MASSs } \\
\text { Some requirements may need to be amended based } \\
\text { on the introduction of new technologies and/or } \\
\text { automated processes. Changes can be made through } \\
\text { the existing Convention processes and flexibilities } \\
\text { through authorized equivalencies or amendments to } \\
\text { the Codes or regulations. }\end{array}$ \\
\hline \multirow[t]{2}{*}{ Degree 2} & $\begin{array}{l}\text { Option 1, Categories I and/or II } \\
\text { (Determination that "remote operator is a seafarer") }\end{array}$ & $\begin{array}{l}\text { Changes to the Convention and Code to establish } \\
\text { definitions and provisions to include the "remote } \\
\text { operator" can be made through the existing } \\
\text { Convention processes and other flexibilities through } \\
\text { authorized equivalencies or amendments to } \\
\text { the Codes or regulations. }\end{array}$ \\
\hline & $\begin{array}{l}\text { Option } 2 \text { Categories I and/or II and/or III } \\
\text { (Determination that "remote operator is not a seafarer") }\end{array}$ & $\begin{array}{l}\text { Provisions necessary to address the "remote } \\
\text { operator" could be established through either } \\
\text { existing instrument(s) other than the STCW } \\
\text { Convention and Code, or a new instrument. }\end{array}$ \\
\hline
\end{tabular}


Table 1. Cont.

\begin{tabular}{cll}
\hline Degree of Autonomy & $\begin{array}{c}\text { The most appropriate way(s) of addressing MASS } \\
\text { operations (I, II, III, IV) }\end{array}$ & $\begin{array}{c}\text { Reasons for selecting the most appropriate way(s) } \\
\text { of addressing MASS operations }\end{array}$ \\
\hline & $\begin{array}{l}\text { Option 1 } \\
\text { Categories I and/or II } \\
\text { (Determination that "remote operator is a seafarer") }\end{array}$ & $\begin{array}{l}\text { Changes to the Convention and Code to establish } \\
\text { definitions and provisions to include the "remote } \\
\text { operator" can be made through the existing } \\
\text { Convention processes and other flexibilities through } \\
\text { authorized equivalencies or amendments to } \\
\text { the Codes or regulations. }\end{array}$ \\
\cline { 2 - 3 } Degree 3 & $\begin{array}{l}\text { The provisions will need to include the relationship } \\
\text { between seafarers on board and the "remote } \\
\text { operator". However, this relationship will also need } \\
\text { to be established in the STCW Convention through } \\
\text { the existing processes and other flexibilities through } \\
\text { authorized equivalencies or amendments to } \\
\text { the Codes or regulations. }\end{array}$ \\
\hline $\begin{array}{l}\text { Option 2 } \\
\text { Categories III } \\
\text { (Determination that "remote operator is not a seafarer") }\end{array}$ & $\begin{array}{l}\text { There are no trained and qualified seafarers serving } \\
\text { on board to perform the operational functions on } \\
\text { board the vessel. }\end{array}$ \\
\hline Categories IV &
\end{tabular}

As identified in MASS RSE step 2 for STCW 1978, as amended, the most important issues for the application of the IMO Convention are the operators of MASSs and their definitions and responsibilities. This conclusion was similarly attributed to the 14 IMO instruments that undertook the MASS RSE during 2018-2020. Therefore, it was confirmed that understanding, identification, and establishment of standards are necessary for the operation of the MASS and the application of the IMO instruments.

Therefore, it has been confirmed through MASS RSE conducted for 2 years that it is necessary to understand, identify, and establish the following three issues for the operation of the MASS and application of the IMO instruments.

1. Clear understanding of the seafarer's task on the vessel under the current IMO instruments.

2. Clear identification of whether are seafarers onboard or not, depending on the degree of autonomy of MASSs, and clear classification of seafarers' or personnel's responsibilities for their tasks onboard.

3. Accordingly, it is required that new standards for the definition of a seafarer, and the clear division of role and responsibilities of staff, remote operators, and the captain, be established.

The number of ship operators basically will decrease or disappear with the introduction of the MASS. Nevertheless, it is expected that human factors in other forms will emerge. Ahvenjärvi [21] concluded that some type of operator errors will be eliminated, while the human element and errors in different forms should be taken into account.

Ramos et al. discussed onboard and onshore operations for the MASS and highlighted that information overload, situation awareness, skill degradation, and boredom have to be taken into account for the operators' performance in a shore control center [10]. Nava and Fernanda [22] argued that a specific aspect for autonomous and unmanned vessels for the STCW convention should take into account legal challenges of liability of collisions from the United Nations Convention on the Law of the Sea (UNCLOS), the Convention on International Regulations for Preventing Collisions at Sea (COLREG), and the STCW 1978 convention. Zhu et al. [11] identified design-based solutions and operation-based solutions in order to resolve human factor challenges such as situation awareness, problem recognition, and decision-making. Sharma et al. [12] suggested that important and relatively less important competences for deck officers for MASS degree 2 take into account the current requirement of the STCW 1978 convention. Mallam et al. [23] suggested human-technology aspects of new operating paradigms and emerging regulatory, liability, and security concerns.

According to the results of the IMO MASS RSE and studies regarding MASS human elements, it can be seen that the design and operation of the MASS relating to human factors are still very important factors. Therefore, the IMO human element, human reliability assessment (HRA), and operational risk assessment take into account that the human element should be actively researched and developed. 
Particularly, it is important that the development of a risk assessment tool for MASS operation takes into consideration the required competence for seafarers and remote operators.

\section{Decision-Making System for MASS Operation}

Decision support technology is essential to enable the operation of ships, especially over MASS degree 3. Among various decision-making systems, decision-making technology for collision avoidance is one of the core technologies for the safe operation of MASSs. Park [24] used the collision risk model (PARK model) to display the risk of collision on the screen so that the officers could help make decisions based on that information. Pietrzykowski et al. [25] proposed a method to reduce ship collision accidents due to human errors by automatically suggesting solutions in color in a collision situation. Additionally, Ożoga and Montewka [26] proposed an algorithm that suggests the safest athlete's defence according to the risk, taking into account the condition of the opposing ship. These technologies can be applied to MASS degrees 1 and 2, but cannot be applied to ships of MASS degree 3 and 4 that have no seafarers and will be controlled by remote operators. Therefore, a technology capable of automatically making decisions based on the collected information is required to avoid the collision of ships.

Perera et al. [27] proposed that a ship collision situation avoidance algorithm based on fuzzy logic, which can be developed and used in decision-making systems in autonomous vessels, and Zhang and Furusho [28] proposed the structure of a decision support system to replace experienced seafarers using a Bayesian network. Zhang et al. [29] suggested that the system can avoid collision through the proposed system based on the collision avoidance linear extension algorithms in various ship operation situations according to the COLREGs regulations. Perera [13] proposed a decision support system to be applied to autonomous ships based on deep learning and presented possible problems and solutions to applying it to MASS operation. Lazarowska [30] proposed a trajectory base algorithm that supports decision making to avoid static and dynamic objects in complex navigation situations. Zhang et al. [31] proposed deep reinforcement learning to achieve intelligent obstacle avoidance of MASS in a port, which is an autonomous navigation decision-making model based on hierarchical deep reinforcement learning. Zhang et al. also suggested that an improved deep reinforcement learning (DRL) algorithm could effectively improve navigation safety and collision avoidance for MASS. While various decision-making technologies are being developed, research on the development of a deep learning-type decision-making system that has been verified through examples applied in vehicles will be strengthened in the future. However, the required technologies to implement and evaluate ship intelligence in transport systems are still in a preliminary stage. Therefore, a considerable amount of effort with future studies will have to be made for that area.

In addition to the collision avoidance decision system, decision systems for various emergency situations based on the degree of autonomy are also required for the safe operation of MASSs. Varela et al. [32] proposed a decision-making system for emergency response in the event of a ship flooding situation. Pennanen et al. [33] developed a system that can provide the flooding level sensor data and the status of the ship's doors to assist crews in making decisions on a submerged passenger ship. This decision support system is applicable on the premise that the seafarer is on board, but since this information is essential for ships with MASS degree 3 or higher, it is necessary to continuously develop reliable technology for responding to a ship flooding situation.

In addition, to support the efficient operation of ships, Beşikçi et al. [14] proposed an artificial neural network decision-making system to help optimize the use of fuel for ships, so that it can be operated efficiently, and Dong et al. [34] have proposed a decision system that selects the optimal route by considering the ship's hull fatigue, sailing time, and exhaust gas reduction. Lee et al. [35] also proposed a decision system that determines the optimal ship speed by considering weather data.

Recently, Gil et al. [36] analyzed research related to decision support systems and classified nine categories (collision avoidance; weather conditions; routing; stability and cargo; engine damage; ship maneuvering; hull loads and damage; ice navigation routing; miscellaneous), with consideration 
for the technology readiness level related to MASS operation. This paper also analyzed the area of application, potential end-users, features, and gaps and limitations.

Issues identified and items to be considered for decision support technology for MASS are presented in Table 2.

Table 2. Suggested decision support or making technology for MASS.

\begin{tabular}{|c|c|c|}
\hline Systems & Tools Suggested & Items to Be Considered \\
\hline Decision-making technology for collision avoidance & $\begin{array}{l}\text { - Collision risk model to display the risk } \\
\text { of collision on the screen } \\
\text { - Automatically suggesting solutions } \\
\text { in color in a collision situation } \\
\text { - Safest athlete's defence according to } \\
\text { the risk, taking into account } \\
\text { the condition of the opposing ship }\end{array}$ & $\begin{array}{l}\text { - Applied to MASS degrees } 1 \text { and 2, but cannot be } \\
\text { applied to ships of MASS degrees } 3 \text { and } 4 \\
\text { - } \quad \text { Research on collision avoidance technology for } \\
\text { MASS degrees } 3 \text { and } 4 \text { must be considered } \\
\text { - } \quad \begin{array}{l}\text { Environmental conditions need to be } \\
\text { considered for feasibility }\end{array} \\
\text { - } \quad \text { Requires additional, dedicated sensors }\end{array}$ \\
\hline $\begin{array}{l}\text { Suggested systems or tools for collision situation } \\
\text { avoidance for MASS }\end{array}$ & 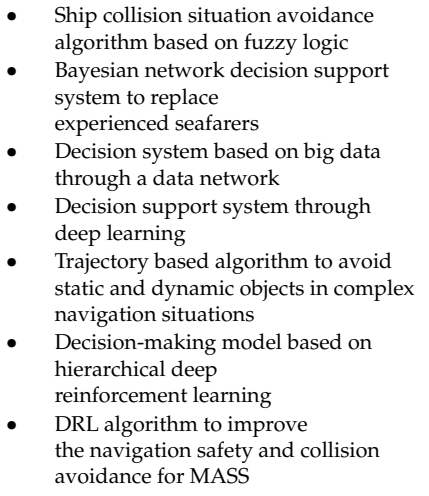 & $\begin{array}{l}\text { - Deep learning-type decision-making system } \\
\text { for MASS }\end{array}$ \\
\hline Another type of decision support system & 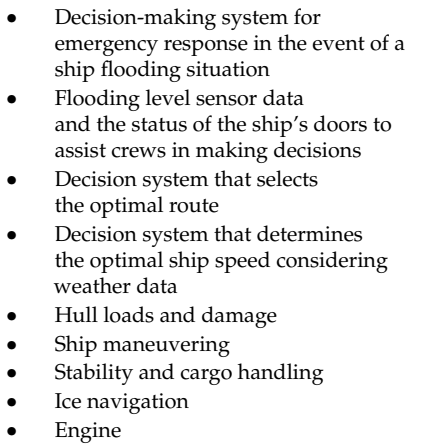 & $\begin{array}{l}\text { - Decision system of emergency cases; selects } \\
\text { optimal route and optimal ship speed for MASS } \\
\text { other than collision avoidance system } \\
\text { - } \\
\text { - } \\
\text { - }\end{array}$ \\
\hline
\end{tabular}

It will be difficult to say which of the technology will evolve into a major technology. However, there is no doubt that decision support or intelligent decision systems to respond to collision avoidance, emergency situations, optimal route determination, and optimal ship speed determination should be applied to the MASS.

\section{Design, Communication and Maintenance Studies of the MASS}

\subsection{Design of MASS}

Looking back in history at the transition of fuels from coal to oil in shipping industries, boilers became smaller and ships could travel twice as far with great speed because oil has double the thermal content of coal. Ships could store oil in tanks anywhere to allow more efficient design of the ships, and refueling at sea was feasible, which provided better flexibility. As a part of "Shipping 4.0" [37], it is likely that we are once again entering a new paradigm shift of ship design and operation, with the introduction of autonomous ships. 
The main task of commercial ships is to transport commodities and people from one port to another. Especially for cargo ships, on which this study focuses, if there is no crew on board, many constraints of the ship's design can be removed. The main difference between autonomous cargo ships over MASS degree 3 from conventional cargo ships will be the removal of the entire deckhouse that has accommodation and systems that serve the crew. This will reduce design, construction, and operation cost, as well as weight and space, which enable the autonomous ships to carry more cargo [38].

In addition, removing the deckhouse will reduce air resistance, which typically represents about $2 \%$ of the total resistance of a vessel, and thus improve ship resistance efficiency [39]. Ship lightweight reduction, while deadweight is maintained as constant and without life-sustaining systems such as heating, ventilation, and air conditioning (HVAC) for the crew as a consequential change, will also reduce electricity and fuel oil consumption.

It is also expected that the autonomous ships will use a wider range of physical sensors than current conventional ships to control autonomous functions, including global positioning system (GPS); inertial navigation system (INS); optical and infra-red (IR) cameras; light detection and ranging (LIDAR); radio detecting and ranging (RADAR); microphones; and wind and pressure sensors. It should be noted that, unlike the cost saved by removing deckhouses from the ships, these will increase costs for the additional sensors and installation, design of system integration, and maintenance with a redundancy of the sensors.

Regarding the propulsion systems, it is expected that autonomous ships will have different engine systems and propulsion configurations compared to most of today's large commercial ships operating with conventional propulsion systems with internal combustion engines. With the rapid development of technology, autonomous ships are likely to introduce fully-electric propulsion systems consisting of electric propulsor, power sources (e.g., lithium-ion batteries, fuel-cells), and control systems. Recently, electric propulsion vessels have been developed and tested all over the world with a variety of multinational projects to make the MASS a reality. However, despite the advantages of the electric propulsion system for the autonomous ship, for propulsion in long-range voyage for international trades, there are still significant developments to be made in order to rely solely on electric power sources, and the space and arrangement of the sources to also be considered. In its early stages, hybrid applications, in combination with a sulfur-free fuel such as LNG, could be a solution for the ship. It is expected that a fully electric propulsion system will have a propulsion drive train that is purely electrically driven, while a hybrid system will have a combined mechanical and electrical propulsion drive train.

The autonomous or unmanned ship also has a high possibility of installing a full-battery power system with a DC-grid instead of an AC-grid for electric propulsion and distribution systems, due to power stability and low economic cost [40]. A DC-grid is more suitable than an AC-grid (currently applied as a standard power system), especially for electric propulsion ships with many variable frequency drives (VFDs) to control motors such as heavy-lifting cranes, propulsion or thruster motors, pumps, and compressors. [41]. Developments in renewable energy, and energy storage systems (ESSs) have supported the growth of the DC-grid. The electric propulsion systems with DC-grids would be applied to the MASS by further demands of the market for cleaner and more efficient electric power, taking into account stricter environmental regulations.

With all these taken into consideration, design changes for autonomous cargo ships above MASS 3 were investigated and are presented with their potential impacts in Table 3.

Regarding the sensors applied to MASS, one of the main functions will be situational awareness of the ship's surroundings, especially in order to avoid grounding and collision with other ships, vessels, people, marine mammals, or other obstacles that may be encountered. Therefore, the reliability of the sensors, which failures can cause a serious threat to the safety of the system, must be ensured through design approval as well as remote and on-premise testing and periodic inspections. 
Table 3. Design changes for autonomous cargo ships over MASS Step 3 and their potential impacts.

\begin{tabular}{|c|c|c|}
\hline Items & Design Changes & Potential Impacts \\
\hline Hull structure & $\begin{array}{ll}\text { - } & \text { Closed structure } \\
\text { - } & \text { External access for } \\
\text { - } & \text { Streaintenance and repair } \\
\text { Stred exterior }\end{array}$ & $\begin{array}{l}\text { - } \quad \text { Reduction of wind resistance } \\
\text { - } \quad \text { Prevention of piracy for crew and cargo }\end{array}$ \\
\hline Deckhouse & $\begin{array}{l}\text { - } \quad \text { No deckhouse; without } \\
\text { accommodation for crew } \\
\text { - } \quad \text { No stairs and doors } \\
\text { - } \quad \text { No sanitary system } \\
\text { - }\end{array}$ & $\begin{array}{l}\text { - } \quad \text { Reduction of ship lightweight } \\
\text { - } \quad \text { Loading more cargo } \\
\text { Reduction of ballast water due to reduced } \\
\text { weight of deckhouse and more cargo }\end{array}$ \\
\hline Machinery & $\begin{array}{ll}\text { - } & \text { No HVAC } \\
\text { and life-sustaining systems }\end{array}$ & $\begin{array}{l}\text { - Small main and auxiliary engines } \\
\text { - } \quad \text { Reduced electrical/fuel consumption }\end{array}$ \\
\hline Propulsion system & $\begin{array}{ll}\text { - } & \text { Electric/hybrid propulsion } \\
\text { system with ESS } \\
\text { - } & \text { Electric propulsor(s) } \\
\text { - } & \text { DC-grid system }\end{array}$ & $\begin{array}{l}\text { - Efficient electric power and reduced } \\
\text { electrical consumption } \\
\text { - } \quad \text { Efficient control of VFDs }\end{array}$ \\
\hline Equipment (sensor) & $\begin{array}{ll}\text { - } & \text { IR cameras, LIDAR, RADAR } \\
\text { - } & \text { High-resolution sonar } \\
\text { - } & \text { Microphones } \\
\text { - } & \text { Homogeneous and/or } \\
& \text { heterogeneous redundancy }\end{array}$ & $\begin{array}{l}\text { Design consideration of installation } \\
\text { and system integration } \\
\text { Potential requirement for remote maintenance } \\
\text { and inspection }\end{array}$ \\
\hline Hull outfitting & $\begin{array}{l}\text { - Fully or semi-automatic } \\
\text { cargo handling } \\
\text { and mooring systems } \\
\text { - No life-saving equipment }\end{array}$ & $\begin{array}{l}\text { - } \quad \text { Boarding crew for cargo handling and port calls } \\
\text { - } \quad \text { Decrease of lighting and ventilation } \\
\text { - } \quad \text { Modified dockside infrastructure } \\
\text { - } \quad \text { Electrical/fuel savings }\end{array}$ \\
\hline
\end{tabular}

Additionally, these changes of ship design require development, amendment, and interpretation of maritime rules and regulations, together with communication and cooperation of multiple stakeholders such as ship designers, equipment manufacturers, shipping companies, classification societies, and international organizations to make the autonomous ships efficient and reliable. The design approach to MASSs should be systematic and iterative and take into account life cycles, involving testing and proofing. The design of the MASS should also be performed by taking into account the involvement of human factors in a completely different way, i.e., operation from shore control center (SCC), not operation directed by an onboard crew, and risk related to the factors [42].

\subsection{Communication System and Cyber Security of MASS}

It is difficult to say that developing an autonomous ship is easier than developing a self-driving vehicle because the sea is much wider than roads and has fewer obstacles. Specific routes or ports where the ships are in operation are more complicated than roads. Moreover, there is no sign to separate the space on the sea like a road lane. In fact, ship collisions occur more than expected.

Operations of the autonomous ships will take place in remote locations, so the wireless communication systems between the ships and the SCC are crucial for their safe and efficient operation. The autonomous ships are expected to adopt more comprehensive communication systems, such as the navigation systems related to positioning and route-setting, marine satellite systems, data communication systems for information related to navigation and safety between 
ships at sea and infrastructures onshore (e.g., SCC, ports), and remote monitoring and control systems. Such communication will need to be bidirectional, robust, accurate, and supported by multiple systems, without creating redundancy and by minimizing risk [38]. The third-party infrastructure, such as satellite or terrestrial communication systems, are expected. Therefore, performance, cybersecurity, and the cost of the systems and their reliability are important issues that need to be tackled.

Today, a manned vessel has from 400 to several thousand sensors that, in one way or another, are reporting data or are used in operation [43]. Autonomous ships are expected to require a wider range of sensors (e.g., optical and IR cameras; LIDAR; RADAR), with navigation systems such as GPS, INS (inertial navigation system) and GMDSS (global maritime distress and safety system), and transmit a huge amount of data to control autonomous functions and help real-time decisions. For example, LiDAR, which can be used to obtain detailed data about the environment, easily requires a few Mbit/s capacity for transmitting the data. The generation of three-dimensional maps of high definition (HD) video also requires few Mbit/s in autonomous navigation scenarios [44]. In addition, sensors related to the status of engines and mechanical parts provide a small amount of critical data to be transferred to the remote operators onshore. In case of emergency situations such as stranding or evasive maneuvering, the ship systems should be remotely monitored and controlled by the operators of the SCC, receiving crucial information via satellite at short time intervals. Therefore, high data rates, data integrity, real-time communications, the resilience of the data transfer, robustness, and security should be taken into consideration for efficient communication between the ships and the SCC.

There has been research on the identification of communication methods and problems between ships and vessels or ships and land and their countermeasures [43-46]. Regarding cybersecurity, if a cyberattack happens to a ship's critical control system, it can cause incidents and casualties such as collision, stranding, and environmental pollution. The authors of $[47,48]$ studied cyberattack scenarios and proposed a system architecture to resolve potential situations. As malicious activity grows and new technologies such as the Internet of Things (IoT) emerge, new security challenges will materialize and the suitable protection of systems, networks, and data in cyberspace will be required.

There are also some concerns on regulations and standardization for the communication system of the MASS as e-navigation and the electronic chart display and information system (ECDIS) will be essential for autonomous ships, with aid from other ship navigation systems such as the automatic identification system (AIS) and river information services for inland waterways. In November 2014, the E-navigation Strategy Implementation Plan (SIP) was approved, where one of the scopes concerned effective and robust communication methods for maritime operations [49]. The SIP is intended to meet present and future user needs through harmonization of marine navigation systems and the support of shore services.

Moreover, the coordinated use of multiple heterogeneous unmanned vehicles such as autonomous underwater vehicles (AUVs), unmanned surface vehicles (USVs), and unmanned aerial vehicles (UAVs) for remote-sensing can be beneficial for several reasons. Not only can different vehicles be used to acquire data in different environments, but they can also improve overall communication performance. Moored or quasi-static systems can be useful, especially in operation areas where environmental hazards do not encourage or permit human presence.

Figure 2 shows MASS and SCC systems with essential equipment and functions and their relationship formed by data and information via satellite.

Communication requirements can be reduced by a higher degree of autonomy where the onboard processing system analyzes the data for detection, tracking, classification, and recognition of objects of interest [50]. However, it should be noted that the higher degree of autonomy a ship has, the more crucial and significant accidents the ship can cause.

Therefore, all the systems, including connectivity, need to be designed so that a single failure should not have a significant impact on the ability of the ship to operate in all relevant modes 
and environments. The communication system supporting autonomous operations is thus considered as an integral part of the safety system.
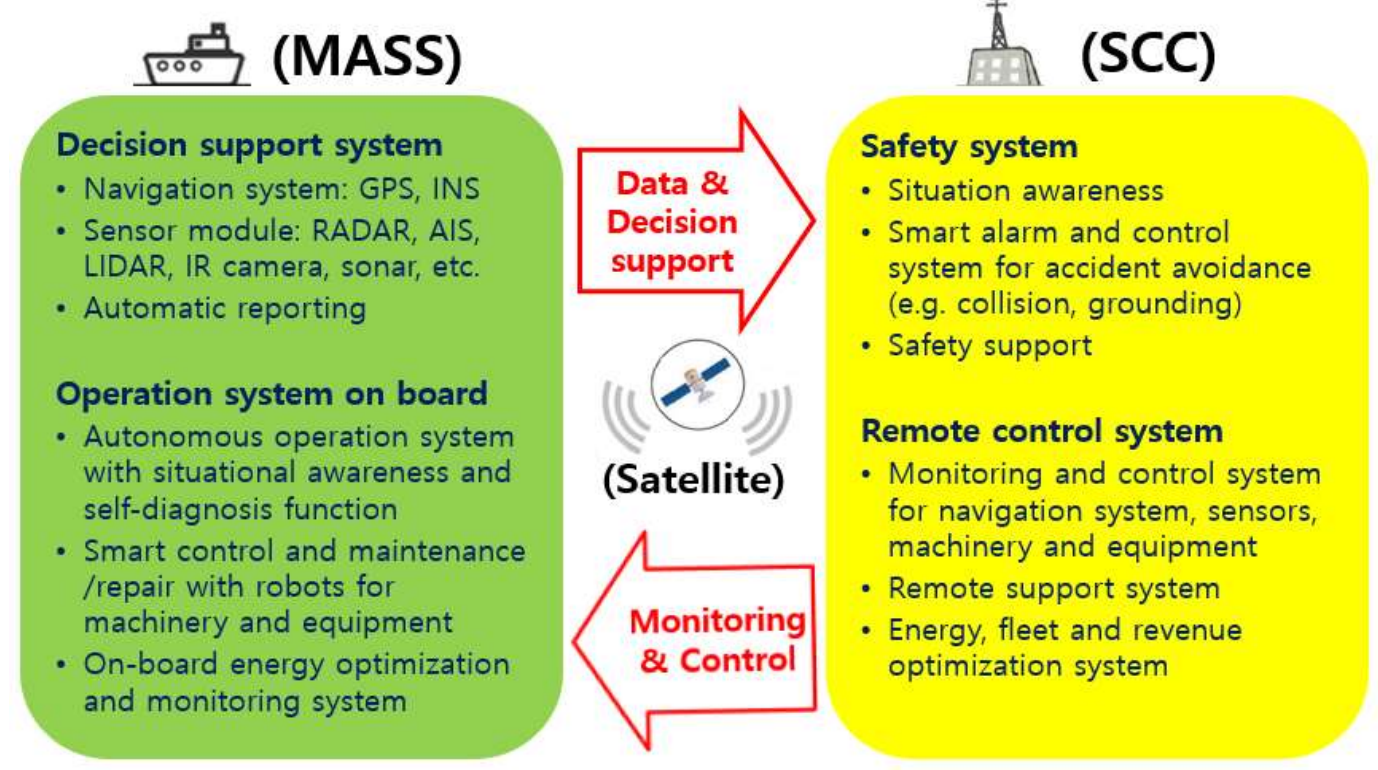

Figure 2. Systems and functions of MASS and SCC and their relationship.

\subsection{Maintenance and Repair}

As there will be no seafarer for maintenance and repair of autonomous ships above MASS degree 3 that are operating in isolation from repair and spares facilities, malfunctions of hardware and software could cause more serious problems than current conventional ships. In addition, the software or hardware malfunctions in daily and periodic operations can propagate on a few other components, and the results of such propagation can be both immediate and devastating [51].

To this end, relevant investigation and studies should be proactively conducted in order to identify potential failures that can defeat the functions of MASSs. It is also necessary as preventative measures to improve reliability in terms of hardware and software functions, solve functional problems through remote diagnosis and selection of applicable and effective tasks, and develop a system to make a ship return to a port as a last measure when the ship cannot function or operate appropriately anymore. With the development of automation technologies, a strategy for predictive maintenance and repair would be a better approach to reduce the potential failures, as well as preventive and corrective manual maintenance that is currently carried out during voyages [38].

One of the most important factors of the safety and seaworthiness of a ship is the proper, daily, periodical, and timely maintenance of all her systems, structures, and hull. There has been much research conducted on developing methods of maintenance and repair to solve challenges even in the maintenance approaches currently applied in shipping. Kooij et al. [52] applied condition-based maintenance (CBM) to a propulsion system to monitor it and send a signal to the engine room crew in case of degradation of its performance. Mokashi et al. [53] proposed reliability-centered maintenance (RCM), which focuses on the maintenance resources that affect the system's reliability, thereby making the maintenance program cost-effective during the life cycle of a ship. One of the principles of RCM is that RCM uses a logic tree to screen maintenance tasks; that is, it uses broad categories of consequences of failure to prioritize failure modes [54]. Another approach is risk-centered maintenance (Risk-CM), which uses a combination of probability and consequence, that is, the risk of prioritizing failure modes [55].

To ensure the sufficient reliability of systems and equipment, including sensors as well as any other devices, both RCM, including CBM and Risk-CM, should be considered to find the appropriate 
solution for maintenance. The MASS is also required to be equipped with a high level of redundancy and durability and to be highly modular to avoid failures as all equipment and device installed onboard will be interconnected and integrated to enable the collection, management, and analysis of data. However, it should be noted that it may not be desirable in shipping where critical systems usually have only a single redundancy failure, which could be catastrophic. Typically, the most important safety sensors should consider homogeneous and/or heterogeneous redundancy, and diagnostics and/or prognosis [56].

Issues identified and items to be considered for maintenance and repair of autonomous cargo ships are presented in Table 4.

Table 4. Issues identified and items to be considered for the maintenance and repair of autonomous cargo ships.

\begin{tabular}{|c|c|c|}
\hline Systems & Issues Identified & Items to Be Considered \\
\hline Maintenance & $\begin{array}{l}\text { - Reliable and redundant propulsion } \\
\text { and maneuvering systems } \\
\text { - Wider adoption of condition monitoring } \\
\text { system with diagnostic } \\
\text { and prognostic functions }\end{array}$ & $\begin{array}{l}\text { - } \quad \text { Maintenance crews when a vessel is in port } \\
\text { - } \quad \text { RCM and Risk-CM systems } \\
\text { - Integrated modules for reliability of systems }\end{array}$ \\
\hline Repair & $\begin{array}{l}\text { - } \quad \text { Repair systems for errors and malfunction } \\
\text { in software } \\
\text { - } \quad \text { Emergency system for firefighting, failure } \\
\text { recovery, and repairs at sea } \\
\text { - } \quad \text { system to make a ship return to a port }\end{array}$ & $\begin{array}{l}\text { - } \quad \text { Resilient and redundant systems for failures } \\
\text { - } \quad \text { Automatic and/or remote system for repair } \\
\text { leaks, moisture, fire and flooding }\end{array}$ \\
\hline
\end{tabular}

Autonomous ships without a crew onboard will call for wider adoption of condition-monitoring systems with efficient diagnostic and prognostic algorithms to assess and reduce the potential risk of failures. They are also likely to require a wider and more complex maintenance scheme in port, taking into account resilience to failures and extension of maintenance intervals.

In addition, due to lack of failure data and no easy access to the data, a more detailed elicitation of experts could be beneficial to resolve black swan issues pertaining to hazards threatening the safe and efficient operations of autonomous ships and evaluate the actual feasibility of the mitigation measures [51].

\section{Hazard Analysis for MASS}

Another important aspect of MASS development is to analyze various hazards of MASSs that can lead to major accidents. Unlike manned ships, autonomous ships are operated by autonomous navigation systems with or without remote control from the SCC, depending on the degree of autonomy, and this might influence the safety of autonomous ships in various ways. On the one hand, the implementation of autonomous navigation systems may improve the safety of autonomous ships because this can eliminate human errors that make up the greatest portion of maritime accidents. It is commonly accepted that human error contributes to approximately $80 \%$ of all types of ship accidents [57]. Especially for collision accidents, human error contributes up to $96 \%$ [58]. Therefore, it is expected that autonomous ships will have a reduced number of navigation-related accidents, like collisions or groundings, compared to conventionally manned ships [51]. On the other hand, autonomous navigation systems may adversely affect safety. The new technologies for autonomous navigation and increased complexity can introduce new hazards and cause unforeseen system interdependencies $[59,60]$. It should also be considered that we currently have a large number of incidents that are prevented by human operators, which would be impossible for autonomous ships [61]. These relationships between autonomous ships and reduced/increased incidents are illustrated in Figure 3. 

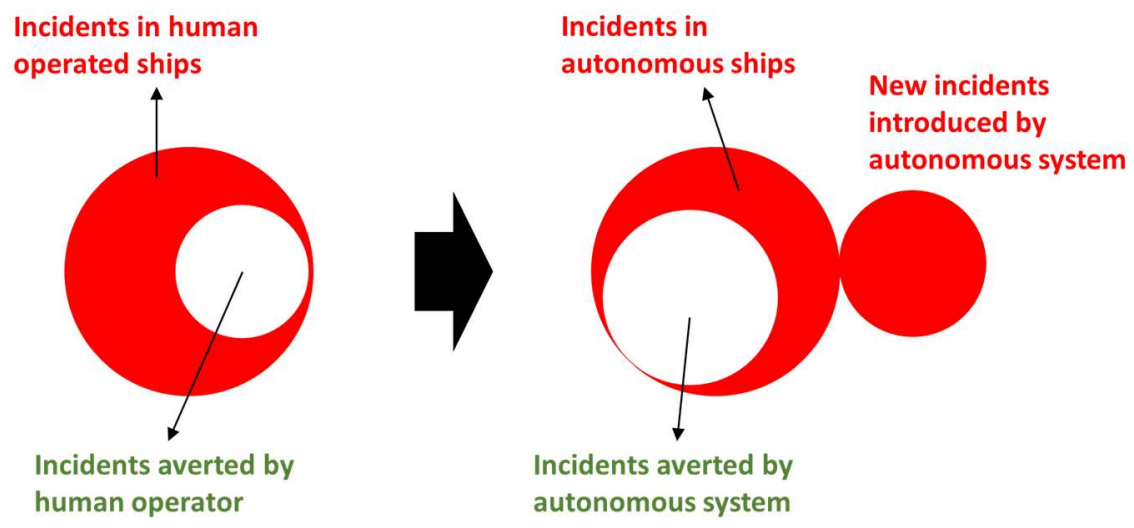

Figure 3. Remaining incidents in the autonomous ship after implementing autonomous navigation systems [59].

For safe operation of autonomous ships, analysis of new hazards of autonomous ships will be needed with the aim of preventing or mitigating the new incidents. We already have commonly used hazard analysis techniques, like failure mode and effect analysis (FMEA), hazard and operability (HAZOP) study, preliminary hazard analysis (PHA), and so on. FMEA was developed in the 1940s to identify problems in military systems, and FMEA is currently required to be integrated into the design process of technical systems in many industries such as defense, aerospace, oil and gas, automobile, and maritime industries. HAZOP was developed in 1963 for the chemical industry, and today, HAZOP has become a standard hazard analysis process for the design of offshore oil and gas platforms and used for hazard analysis in many different application areas [62].

However, there is an argument that these traditional methods developed in the 1940s and 1960s are not appropriate to analyze the hazards of modern, complex, and software-intensive systems like autonomous ships. Leveson [63] argued that these traditional methods are inadequate to analyze hazards of very complex systems because traditional methods mostly focus on failure events and the role of component failures, which are not the main causes of the accidents of modern complex systems. She also claimed that adding new features to traditional hazard analysis methods were not successful, because the underlying assumptions of traditional methods do not account for the actual hazards of modern complex systems. Hollnagel [64] argued that traditional safety efforts, including traditional hazard analysis methods, focused on unwanted or negative outcomes so that they do not apply to intractable systems. Intractable systems are defined as systems whose descriptions elaborate on many details, where the rate of change is high, comprehensibility is low, and the characteristics of processes are heterogeneous and possible irregular; autonomous ships can be classified as an intractable system. Therefore, a couple of new methods have been developed to analyze the hazards of modern, complex, and software-intensive socio-technical systems, and these new methods have been applied to hazard analysis for autonomous ships recently.

STPA is a relative new hazard analysis technique based on the system-theoretic accident model and processes (STAMP). While the main focus of traditional accident casualty models is a chain of directly related failure events or component failures, STAMP explains that the accidents of modern complex systems can also occur by unsafe interactions among system components without any failure events. With this underlying principle, STPA is capable of analyzing the hazards of unsafe interactions (controls and feedbacks), as well as component failures (execution of control actions) [65]. STPA has been widely used in various industries and sectors such as aviation, aerospace, defense, nuclear power plants, oil and gas industries, automobiles, cybersecurity, and so on, and this method has been gaining interest and application in the maritime domain recently [66], especially for the hazard analysis of autonomous ships. For instance, Wróbel et al. [67] applied STPA to develop and analyze a preliminary model of autonomous ships. Banda et al. [68] presented a systematic hazard management process for the concept design of autonomous ships using STPA. Kim et al. [60] applied STPA to 
compare hazards associated with different ship autonomy types, and Wróbel et al. [69] investigated the uncertainties of autonomous ships using STPA. The efforts to improve the safety of autonomous ships using STPA are expected to grow further, based on the fact that STPA is a tailor-made hazard analysis method for analysis of modern complex systems and is already widely used for the analysis of many different complex and autonomous systems.

The FRAM is also a relatively new method to model and analyze complex operations and activities in socio-technical systems, and this method is based on a new safety paradigm, resilience engineering [64]. Resilience means the ability that a system can recognize and adapt to handle unanticipated situations, and therefore, resilience engineering focuses on improving the ability of a system to succeed, while the traditional safety approaches aim to reduce the number of failures or adverse events [70]. The main goal of FRAM is to understand complex functions and activities of socio-technical systems in order to achieve more resilient systems [71], and FRAM has been widely adopted for both risk assessment and accident analysis of various industries and sectors, like aviation, nuclear power plants, oil refinery, railway security, and so on [72]. The potential of FRAM for the hazard analysis of autonomous ships has been discussed by several studies. Chaal et al. [73] emphasized that that FRAM (together with STPA) can contribute to the safe deployment of autonomous ships. Basnet et al. [74] concluded that FRAM and STPA can be optimal methods to analyze the hazards of complex and interconnected systems of autonomous ships, and Relling et al. [75] argued that systemic safety models (like FRAM and STAMP) can be candidates for assessing safety in designing autonomous ships. While the number of studies that apply or discuss FRAM for autonomous ship hazard analysis is comparatively lower than that of STPA, these studies support that FRAM can also be a possible candidate method to analyze the hazards of autonomous ships.

In addition to STPA and FRAM, there have been several studies that discuss applying a new method or model to analyze the hazards of autonomous ships. Basnet et al. [76] explored the applicability of system modeling language (SysML) and object process methodology (OPM) to autonomous ships. Montewka et al. [15] investigated risk-informed design, goal-based safety case approach, and STPA for the risk assessment of autonomous ships. Thieme et al. [16] analyzed 64 risk models for ship collision and groundings to examine their applicability to autonomous ships, and Hoem [77] reviewed the Bayesian belief network (BBN), the human factors analysis and classification system (HFACS) framework, and STPA, and discussed the future of risk assessments of autonomous ships.

All studies explored above support the fact that traditional hazard analysis methods and accident models are not sufficient to analyze hazards and ensure the safe operation of autonomous ships. We need to apply a new hazard analysis method or use new methods along with traditional methods, and further studies must be carried out to identify optimal method(s) for hazard analysis of autonomous ships and to standardize the hazard analysis procedure of autonomous ships in the maritime industry.

\section{Conclusions}

We are once again standing in a transition period of ship design and operation with the introduction of autonomous ships. Therefore, the research approach to MASSs is currently taking place in various directions. This study has analyzed the current trends in six major research fields that must be performed to realize MASS operation among these studies and has suggested considerations and directions for future research.

Firstly, IMO MASS RSE work has been reviewed and presented in the paper. The most important issues for the application of the IMO Conventions among various issues are the operators (seafarer, remote operator) of MASSs and their definitions and responsibilities. Therefore, a clear understanding of the seafarer's task on the vessel under the current IMO instruments is necessary for the revision, development, and application of the IMO Conventions. Based on this, a clear identification whether seafarers are onboard or not, depending on the degree of autonomy of the MASS, and clear classification of seafarers' or personnel's responsibilities for their tasks onboard is necessary, and, new standards for the definition of seafarer and a clear division of the roles and responsibilities of staff, remote operators, 
and the captain are required to be established. Therefore, the results of MASS RSE have clearly shown that human elements are still very important issues to be taken into account for the successful design and operation of the MASS.

Secondly, decision-making/support systems are the most essential technology for the realization of MASSs. In particular, the decision-making system for ship collision avoidance is an essential function for the operation of the MASS, and various studies have been conducted. However, since the research/development for MASS decision-making systems to date has been focused on MASS degrees 1 and 2, it was confirmed that it is necessary to focus on the research on MASS degrees 3 and 4 in the future. To this end, research on a deep-learning decision-making system that has been applied to automobiles among various methods has been proposed as one of the appropriate tools. Additionally, it was identified that an indepth study of decision systems of emergency response, selecting optimal routes and ship speeds for MASSs, is necessary for the safe operation of MASSs to take into account persons such as remote operators and seafarers.

Thirdly, potential design changes for an autonomous commercial cargo ship over MASS degree 3 have been investigated and presented in the paper. If there is no crew on board, especially for a commercial cargo ship, many constraints of the ship's design can be removed. It is expected that the removal of the entire deckhouse from conventional cargo ships could reduce design and construction costs, ship resistance efficiency, and electricity and fuel oil consumption. However, the autonomous ship will use a wider range of physical sensors than current conventional ships to control autonomous functions. Regarding the propulsion system, the autonomous ship is likely to employ fully-electric propulsion systems consisting of electric propulsor, power sources (e.g., lithium-ion batteries, fuel-cells) and control systems with DC-grids for electric propulsion and distribution systems due to power stability and low economic cost. For the successful and efficient design of the ship, maritime rules and regulations should be amended and newly developed together with the cooperation of all stakeholders.

Fourthly, the communication system and cybersecurity of the autonomous ship have been discussed with their development direction in the near future. As an autonomous ship will be operated in remote locations, the wireless communication systems between the ships and the SCC are crucial for their safe and efficient operation. Therefore, the communication system will need to be bidirectional, robust, accurate, and supported by multiple systems, without creating redundancy and by minimizing risk with third-party infrastructures. High data rates, real-time communication, and integrity of data should be taken into consideration with the resilience of data transfer and robustness for the development of the communication system for efficient communication between an autonomous ship and the SCC, the ship and satellites, the ship and other manned/unmanned ships, and even the ship and multiple vehicles such as AUVs, USVs, UAVs for the data acquisition of environment data. In addition, as malicious activities grow and new technologies emerge, new security challenges will materialize, and the suitable protection of systems, networks, and data in cyberspace will be required as an integral part of a safety system.

Fifthly, issues for maintenance and repair of the autonomous ship have been identified with items to be considered. As there will be no seafarers onboard for maintenance and repair, preventative measures are essential to improve reliability in terms of hardware and software functions, solve functional problems through remote diagnosis and selection of applicable and effective tasks, and develop a system to make a ship return to a port as a last measure when the ship cannot function or operate appropriately anymore. To ensure the reliability of systems and equipment, both RCM, including CBM and Risk-CM, should be considered to find an appropriate solution for maintenance, with a strategy of redundancy and diagnostics and/or prognosis. Furthermore, a more detailed elicitation of experts will be beneficial to resolve black swan issues pertaining to hazards threatening the safe and efficient operations of autonomous ships and evaluate the actual feasibility of the mitigation measures.

Lastly, hazard analysis of the autonomous ship has been explored in the paper. The autonomous operation has both positive and negative influences on the safety of the vessel, and it is needed to identify 
reduced/increased hazards to ensure the efficient and safe operation of autonomous ships. However, traditional hazard analysis methods developed several decades ago may not be suitable to analyze hazards of modern, complex, and software-intensive autonomous systems, so relatively new methods need to be developed and applied to analyze the hazards of autonomous ships. STPA and FRAM are identified as the most representative new methods that can be used for hazard analysis of autonomous ships, and we could also find several studies that have applied other new methods, such as SysML, OPM, BBN, and HFACS. While each study suggested a different hazard analysis method, they commonly argued that traditional methods are not sufficient to ensure the safety of autonomous ships. Further studies should be carried out, and guidelines need to be developed to identify optimal hazard analysis method(s) for autonomous ships.

In this study, trends of major research areas for the realization of MASSs are identified. The six areas mentioned above will require continuous and detailed studies. In addition, for the actual operation of the MASS, studies on the definitions of seafarer and remote operator must be carried out promptly, and studies that have been focused on MASS degrees 1 and 2 so far need to be extended to future research considering degrees 3 and 4 .

Author Contributions: C.-J.C.: overall structure, conceptualization, and chpater 1, 2, 3 and conclusions; M.K.: conceptualization, review and chapter 4; H.-J.K.: review and chapter 5. All authors have read and agreed to the published version of the manuscript.

Funding: This research received no external funding.

Conflicts of Interest: The authors declare no conflict of interest.

\section{References}

1. Gray, D. Automation in Ships. In Automation on Shipboard; Bonwick, G., Ed.; MacMillan and Company: New York, NY, USA, 1967; pp. 19-34.

2. Porathe, T.; Burmeister, H.-C.; Rødseth, Ø.J. Maritime unmanned navigation through intelligence in networks: The MUNIN Project. In Proceedings of the 12th International Conference on Computer and IT Applications in the Maritime Industries, COMPIT'13, Cortona, Italy, 15-17 April 2013.

3. Tvete, H. ReVolt: The Unmanned, Zero Emission, Short Sea Ship of the Future; Dnv Gl Strategic Research \& Innovation: Høvik, Norway, 2015.

4. Kongsberg. Autonomous Shipping. 2020. Available online: https://www.kongsberg.com/maritime/support/ themes/autonomous-shipping/ (accessed on 7 January 2020).

5. NYK. NYK Conducts World's First Maritime Autonomous Surface Ships Trial. 2019. Available online: https://www.nyk.com/english/news/2019/20190930_01.html (accessed on 14 January 2020).

6. Herald, T.K. South Korea Embarks on Ambitious Autonomous Ship Project. 2019. Available online: http://www.koreaherald.com/view.php?ud=20191030000699 (accessed on 17 December 2019).

7. YARA. Yara Birkeland Press Kit. 2020. Available online: https://www.yara.com/news-and-media/press-kits/ yara-birkeland-press-kit/ (accessed on 7 January 2020).

8. IMO. Regulatory Scoping Exercise for the Use of Maritime Autonomous Surface Ships (MASS); MSC 99/WP.9; IMO: London, UK, 2018.

9. IMO. Summary of Results of the Second Step of the RSE for STCW Convention and Code. In Regulatory Scoping Exercise for the Use of Maritime Autonomous Surface Ships (MASS); IMO: London, UK, 2020.

10. Ramos, M.A.; Utne, I.; Mosleh, A. On factors affecting autonomous ships operators performance in a Shore Control Center. In Proceedings of the 14th Probabilistic Safety Assessment and Management, Los Angeles, CA, USA, 16-21 September 2018.

11. Zhu, T.; Haugen, S.; Liu, Y. Human Factor Challenges and Possible Solutions for the Operation of Highly Autonomous Ships. In Proceedings of the 29th European Safety and Reliability Conference, Hannover, Germany, 22-26 September 2019.

12. Sharma, A.; Kim, T.; Nazir, S.; Chae, C. Catching up with time? Examining the STCW competence framework for autonomous shipping. In Proceedings of the Ergoship Conference, Haugesund, Norway, 24-25 September 2019. 
13. Perera, L.P. Autonomous ship navigation under deep learning and the challenges in COLREGs. In Proceedings of the 37th International Conference on Ocean, Offshore and Arctic Engineering, Madrid, Spain, 17-22 June 2018.

14. Beşikçi, E.B.; Arslan, O.; Turan, O.; Ölçer, A. An artificial neural network based decision support system for energy efficient ship operations. Comput. Oper. Res. 2016, 66, 393-401. [CrossRef]

15. Montewka, J.; Wróbel, K.; Heikkilä, E.; Banda, O.A.V.; Goerlandt, F.; Haugen, S. Challenges, solution proposals and research directions in safety and risk assessment of autonomous shipping. In Proceedings of the 14th Probabilistic Safety Assessment and Management, Los Angeles, CA, USA, 16-21 September 2018.

16. Thieme, C.A.; Utne, I.B.; Haugen, S. Assessing ship risk model applicability to Marine Autonomous Surface Ships. Ocean Eng. 2018, 165, 140-154. [CrossRef]

17. Rødseth, Ø.J.; Burmeister, H.-C. Risk Assessment for an Unmanned Merchant Ship. TransNav Int. J. Mar. Navig. Saf. Sea Transp. 2015, 9, 357-364. [CrossRef]

18. IMO. Maritime Autonomous Surface Ships (MASS) Proposal for a Regulatory Scoping Exercise; IMO: London, UK, 2017.

19. IMO. Regulatory Scoping Exercise for the Use of Maritime Autonomous Surface Ships (MASS); MSC 99/5; IMO: London, UK, 2020.

20. IMO. International Convention on Standard of Training, Certification and Watchkeeping for Seafarers; IMO: London, UK, 2017.

21. Ahvenjärvi, S. The Human Element and Autonomous Ships. TransNav Int. J. Mar. Navig. Saf. Sea Transp. 2016, 10, 517-521. [CrossRef]

22. Nava, G.; Fernanda, P.M. Legal Challenges of Liability in Collisions Arising from the Development of Autonomous and Unmanned Shipping-International and Norwegian Perspective. Master's Thesis, University of Oslo, Oslo, Norway, 2019.

23. Mallam, S.; Nazir, S.; Sharma, A. The human element in future Maritime Operations-Perceived impact of autonomous shipping. Ergonomics 2019, 63, 334-345. [CrossRef]

24. Park, S.; Park, Y.; Park, J.; Thanh, N. PARK Model and Decision Support System based on Ship Operator's Consciousness. Inf. Commun. Environ 2015, 93-98. [CrossRef]

25. Pietrzykowski, Z.; Wołejsza, P.; Borkowski, P. Decision Support in Collision Situations at Sea. J. Navig. 2016, 70, 447-464. [CrossRef]

26. Ożoga, B.; Montewka, J. Towards a decision support system for maritime navigation on heavily trafficked basins. Ocean Eng. 2018, 159, 88-97. [CrossRef]

27. Perera, L.P.; Carvalho, J.P.; Soares, C.G. Fuzzy logic based decision making system for collision avoidance of ocean navigation under critical collision conditions. J. Mar. Sci. Technol. 2010, 16, 84-99. [CrossRef]

28. Zhang, R.; Furusho, M. Constructing a decision-support system for safe ship-navigation using a Bayesian network. In International Conference on Digital Human Modeling and Applications in Health, Safety, Ergonomics and Risk Management; Springer: Cham, Switzerland, 2016.

29. Zhang, J.; Zhang, D.; Yan, X.; Haugen, S.; Soares, C.G. A distributed anti-collision decision support formulation in multi-ship encounter situations under COLREGs. Ocean Eng. 2015, 105, 336-348. [CrossRef]

30. Lazarowska, A. A new deterministic approach in a decision support system for ship's trajectory planning. Expert Syst. Appl. 2017, 71, 469-478. [CrossRef]

31. Zhang, X.; Wang, C.; Liu, Y.; Chen, X. Chen Decision-Making for the Autonomous Navigation of Maritime Autonomous Surface Ships Based on Scene Division and Deep Reinforcement Learning. Sensors 2019, 19, 4055. [CrossRef]

32. Varela, J.; Rodrigues, J.M.; Soares, C.G. On-board Decision Support System for Ship Flooding Emergency Response. Procedia Comput. Sci. 2014, 29, 1688-1700. [CrossRef]

33. Pennanen, P.; Ruponen, P.; Ramm-Schmidt, H. Integrated Decision Support System for increased Passenger Ship Safety. Damaged SHIP III; Royal Institution of Naval Architects: London, UK, 2015.

34. Dong, Y.; Frangopol, D.M.; Sabatino, S. A decision support system for mission-based ship routing considering multiple performance criteria. Reliab. Eng. Syst. Saf. 2016, 150, 190-201. [CrossRef]

35. Lee, H.; Aydin, N.; Choi, Y.; Lekhavat, S.; Irani, Z. A decision support system for vessel speed decision in maritime logistics using weather archive big data. Comput. Oper. Res. 2018, 98, 330-342. [CrossRef]

36. Gil, M.; Wróbel, K.; Montewka, J.; Goerlandt, F. A bibliometric analysis and systematic review of shipboard Decision Support Systems for accident prevention. Saf. Sci. 2020, 128, 104717. [CrossRef] 
37. Rødseth, Ø. Towards Shipping 4.0. Proceedings of Smart Ship Technology; Royal Institution of Naval Architects: London, UK, 2017.

38. Laurinen, M. Remote and Autonomous Ships: The Next Steps; AAWA: Advanced Autonomous Waterborne Applications: London, UK, 2016.

39. Kretschmann, L.; Burmeister, H.-C.; Jahn, C. Analyzing the economic benefit of unmanned autonomous ships: An exploratory cost-comparison between an autonomous and a conventional bulk carrier. Res. Transp. Bus. Manag. 2017, 25, 76-86. [CrossRef]

40. Kim, K.; Park, K.; Roh, G.; Chun, K. DC-grid system for ships: A study of benefits and technical considerations. J. Int. Marit. Saf. Environ. Aff. Shipp. 2018, 2, 1-12. [CrossRef]

41. Geertsma, R.; Negenborn, R.; Visser, K.; Hopman, J. Design and control of hybrid power and propulsion systems for smart ships: A review of developments. Appl. Energy 2017, 194, 30-54. [CrossRef]

42. Montewka, J.; Goerlandt, F.; Innes-Jones, G.; Owen, D.; Hifi, Y.; Puisa, R. Enhancing human performance in ship operations by modifying global design factors at the design stage. Reliab. Eng. Syst. Saf. 2017, 159, 283-300. [CrossRef]

43. Zolich, A.; Palma, D.; Kansanen, K.; Fjørtoft, K.; Sousa, J.; Johansson, K.H.; Jiang, Y.; Dong, H.; Johansen, T.A. Survey on Communication and Networks for Autonomous Marine Systems. J. Intell. Robot. Syst. 2018, 95, 789-813. [CrossRef]

44. Seif, H.G.; Hu, X. Autonomous Driving in the iCity-HD Maps as a Key Challenge of the Automotive Industry. Engineering 2016, 2, 159-162. [CrossRef]

45. Rødseth, Ø.J.; Lee, K. Secure communication for e-navigation and remote control of unmanned ships. In Proceedings of the 14th Conference on Computer and IT Applications in the Maritime Industries-COMPIT, Ulrichshusen, Germany, 11-13 May 2015.

46. Schiaretti, M.; Chen, L.; Negenborn, R.R. Survey on autonomous surface vessels: Part II-Categorization of 60 prototypes and future applications. In Proceedings of the International Conference on Computational Logistics, Southampton, UK, 18-20 October 2017.

47. Hogg, T.; Ghosh, S. Autonomous merchant vessels: Examination of factors that impact the effective implementation of unmanned ships. Aust. J. Marit. Ocean Aff. 2016, 8, 206-222. [CrossRef]

48. Kavallieratos, G.; Katsikas, S.; Gkioulos, V. Cyber-Attacks Against the Autonomous Ship. In Computer Security; Springer: Cham, Switzerland, 2018.

49. IMO. E-Navigation Strategy Implementation Plan-Update 1; IMO: London, UK, 2018.

50. Leira, F.S.; Johansen, T.A.; Fossen, T.I. Automatic detection, classification and tracking of objects in the ocean surface from UAVs using a thermal camera. In Proceedings of the 2015 IEEE Aerospace Conference, Big Sky, MT, USA, 7-14 March 2015; Institute of Electrical and Electronics Engineers (IEEE): Piscataway, NJ, USA; pp. 1-10.

51. Wróbel, K.; Montewka, J.; Kujala, P. Towards the assessment of potential impact of unmanned vessels on maritime transportation safety. Reliab. Eng. Syst. Saf. 2017, 165, 155-169. [CrossRef]

52. Kooij, C.; Loonstijn, M.; Hekkenberg, R.G.; Visser, K. Towards autonomous shipping: Operational challenges of unmanned short sea cargo vessels. In Marine Design XIII; Kujala, P., Lu, L., Eds.; Taylor \& Francis Group: Espoo, Finland, 2018; pp. 871-880.

53. Mokashi, A.; Wang, J.; Vermar, A. A study of reliability-centred maintenance in maritime operations. Mar. Policy 2002, 26, 325-335. [CrossRef]

54. NASA. Reliability-Centred Maintenance Guide for Facilities and Collateral Equipment; NASA Office of Safety and Mission Assurance: Washington, DC, USA, 2000.

55. Jones, R.B. Risk-Based Management: A Reliability-Centered Approach; Gulf Publishing Company: Houston, TX, USA, 1995.

56. DNV GL. Remote-Controlled and Autonomous Ships in the Maritime Industry; Group Technology and Research, Position Paper; DNV GL-Maritime: Hamburg, Germany, 2018.

57. Portela, R.D.L.C. Maritime casualties analysis as a tool to improve research about human factors on maritime environment. J. Marit. Res. 2005, 2, 3-18.

58. Dhillon, B.S. Human Reliability and Error in Transportation Systems; Springer Science \& Business Media: London, UK, 2007. 
59. Utne, I.B.; Sørensen, A.J.; Schjølberg, I. Risk Management of Autonomous Marine Systems and Operations. In Proceedings of the 36th International Conference on Ocean, Offshore and Arctic Engineering, American Society of Mechanical Engineers Digital Collection, Trondheim, Norway, 25-30 June 2017.

60. Kim, H.; Haugen, O.I.; Rokseth, B.; Lundteigen, M.A. Comparison of Hazardous Scenarios for Different Ship Autonomy Types using Systems-Theoretic Process Analysis. In Proceedings of the 29th European Safety and Reliability Conference (ESREL), Hannover, Germany, 22-26 September 2019.

61. Porathe, T.; Hoem, Å.; Rødseth, Ø.; Fjørtoft, K.; Johnsen, S. At least as safe as manned shipping? Autonomous shipping, safety and "human error." Safety and Reliability-Safe Societies in a Changing World. In Proceedings of the ESREL 2018, Trondheim, Norway, 17-21 June 2018.

62. Rausand, M. Risk Assessment: Theory, Methods, and Applications; John Wiley \& Sons: Hoboken, NJ, USA, 2013; Volume 115.

63. Leveson, N. Engineering a Safer World, Systems Thinking Applied to Safety (Draft); MIT Press: Cambridge, MA, USA, 2011.

64. Hollnagel, E. FRAM, The Functional Resonance Analysis Method: Modelling Complex Socio-Technical Systems; Ashgate Publishing, Ltd.: Farnham, UK, 2013.

65. Leveson, N.G.; Thomas, J.P. STPA Handbook; Massachusetts Institute of Technology: Cambridge, MA, USA, 2018.

66. Gil, M.; Wróbel, K.; Montewka, J. Toward a Method Evaluating Control Actions in STPA-Based Model of Ship-Ship Collision Avoidance Process. J. Offshore Mech. Arct. Eng. 2019, 141, 051105. [CrossRef]

67. Wrobel, K.; Krata, P.; Montewka, J. Preliminary Results of a System-theoretic Assessment of Maritime Autonomous Surface Ships' Safety. TransNav, Int. J. Mar. Navig. Saf. Sea Transp. 2019, 13, 717-723. [CrossRef]

68. Banda, O.A.V.; Kannos, S.; Goerlandt, F.; Van Gelder, P.H.; Bergström, M.; Kujala, P. A systemic hazard analysis and management process for the concept design phase of an autonomous vessel. Reliab. Eng. Syst. Saf. 2019, 191, 106584. [CrossRef]

69. Wróbel, K.; Montewka, J.; Kujala, P. Towards the development of a system-theoretic model for safety assessment of autonomous merchant vessels. Reliab. Eng. Syst. Saf. 2018, 178, 209-224. [CrossRef]

70. Hollnagel, E. Resilience Engineering in Practice: A Guidebook; Ashgate Publishing, Ltd.: Farnham, UK, 2013.

71. De Carvalho, P.V.R. The use of Functional Resonance Analysis Method (FRAM) in a mid-air collision to understand some characteristics of the air traffic management system resilience. Reliab. Eng. Syst. Saf. 2011, 96, 1482-1498. [CrossRef]

72. Patriarca, R.; Patriarca, G.D.G.A.R.; Costantino, F.; Tronci, M. The Functional Resonance Analysis Method for a systemic risk based environmental auditing in a sinter plant: A semi-quantitative approach. Environ. Impact Assess. Rev. 2017, 63, 72-86. [CrossRef]

73. Chaal, M.; Banza, O.A.V.; Basnet, S.; Hirdaris, S.E.; Kujala, P. An initial hierarchical systems structure for systemic hazard analysis of autonomous ships. In Proceedings of the International Seminar on Safety and Security of Autonomous Vessels (ISSAV) and European STAMP Workshop and Conference (ESWC) 2019, Sciendo, Finland, 17-20 September 2019.

74. Basnet, S.; Banda, O.A.V.; Hirdaris, S.E. The management of risk in autonomous marine ecosystems-Preliminary ideas. In Proceedings of the International Workshop on Autonomous Systems Safety, Trondheim, Norway, 11-13 March 2019.

75. Relling, T.; Lützhöft, M.; Ostnes, R.; Hildre, H.P. A Human Perspective on Maritime Autonomy. In International Conference on Augmented Cognition; Springer: Cham, Switzerland, 2018.

76. Basnet, S.; Banza, O.A.V.; Chaal, M.; Hirdaris, S.E.; Kujala, P. Comparison of system modelling techniques for autonomous ship systems. In Proceedings of the International Seminar on Safety and Security of Autonomous Vessels (ISSAV) and European STAMP Workshop and Conference (ESWC) 2019, Sciendo, Finland, 17-20 September 2019.

77. Hoem, A.S. The present and future of risk assessment of MASS: A literature review. In Proceedings of the 29th European Safety and Reliability Conference (ESREL), Hannover, Germany, 22-26 September 2019.

(C) 2020 by the authors. Licensee MDPI, Basel, Switzerland. This article is an open access article distributed under the terms and conditions of the Creative Commons Attribution (CC BY) license (http://creativecommons.org/licenses/by/4.0/). 